\title{
A Mechanism of Gold Nanoparticle Aggregation by Immunoglobulin G Preparation
}

\author{
Dmitriy V. Sotnikov ${ }^{1}$, Irina V. Safenkova ${ }^{1}$, Anatoly V. Zherdev ${ }^{1}\left(\mathbb{D}\right.$, Vadim G. Avdienko ${ }^{2}$, \\ Irina V. Kozlova ${ }^{2}$, Suren S. Babayan ${ }^{2}$, Vladislav Ya. Gergert ${ }^{2}$ and Boris B. Dzantiev ${ }^{1, *(1)}$ \\ 1 A.N. Bach Institute of Biochemistry, Research Center of Biotechnology of the Russian Academy of Sciences, \\ Leninsky prospect 33, 119071 Moscow, Russia; sotnikov-d-i@mail.ru (D.V.S.); saf-iri@yandex.ru (I.V.S.); \\ zherdev@inbi.ras.ru (A.V.Z.) \\ 2 Central Tuberculosis Research Institute, Yauz alley 2, 107564 Moscow, Russia; vg_avdienko@mail.ru (V.G.A.); \\ ikozlova_work@inbox.ru (I.V.K.); suren.babayan@mail.ru (S.S.B.); hergertv@mail.ru (V.Y.G.) \\ * Correspondence: boris.dzantiev@mail.ru; Tel.: +7-(495)-954-31-42
}

Received: 26 November 2019; Accepted: 7 January 2020; Published: 9 January 2020

Featured Application: Aggregation instability of conjugates of gold nanoparticles and antibodies is a frequent problem. Widely used screening antibody clones to find the most stable conjugates is an extensive approach to solve the problem. We have found that a partial destruction of antibodies may cause the decrease in the stability of conjugates. So the control of the preparations used and removing products of the antibodies decay will assist in the creation of nanoconjugate-based systems with enhanced functionality.

Abstract: Conjugates of gold nanoparticles (GNPs) and antibodies are widely used in various fields of biochemistry and microbiology. However, the procedure for obtaining such conjugates remains precarious, and the properties of conjugates differ significantly for different antibody clones. One of the most common problems is the aggregation of GNPs in the course of their conjugation with antibodies. This article considers an example of the conjugation of monoclonal antibodies with non-stable aggregating product. The composition of the antibody preparation was studied using electrophoresis, asymmetrical flow field-flow fractionation, and ultracentrifugation. It was shown that the component that causes the aggregation of the GNPs is the light chains of immunoglobulins that appear due to the spontaneous decay of the antibodies. After separation of the fraction with a molecular weight of less than $30 \mathrm{kDa}$, stable conjugates of antibodies with GNPs were obtained. The high functional activity of the obtained conjugates was confirmed by immunochromatography.

Keywords: gold nanoparticles; conjugation; immobilization; flocculation; fragments of antibodies

\section{Introduction}

Due to the unique physical and chemical properties of gold nanoparticles (GNPs), they are widely used in biochemistry, medicine, and analytical chemistry [1-6]. GNPs have high surface energy, which determines the possibility of their modification $[7,8]$. As a rule, GNPs are modified using biological macromolecules such as proteins and nucleic acids $[9,10]$. GNPs in complexes with bioreceptor molecules (antibodies, aptamers, etc.) are used as analytical markers [11,12]. To obtain nanoconjugates, a large number of covalent sewing techniques have been developed, but for biological macromolecules, physical adsorption methods remain the most popular [13-15].

The interaction of macromolecules and nanoparticles depends on the chemical nature of the adsorbed substance, the composition of the medium, and other factors. Electrostatic, hydrophobic, van der Waals, and donor-acceptor interactions can contribute to this process [6]. The high 
affinity of gold for sulfur-containing groups leads to the formation of a self-organizing monolayer of thiol-containing molecules on gold surfaces [16]. Proteins are effective stabilizers for GNPs. Even physical sorption of proteins on the surface of gold is characterized by a high binding constant $\left(K_{d}\right.$-up to $\left.10^{-9} \mathrm{M}\right)[17,18]$. As well as proteins contain many groups with different natures, their interaction with the surfaces of particles occurs by several mechanisms.

Despite the long history of the use of GNPs, the synthesis of their conjugates with biomolecules is not a strictly delineated procedure to this day. The syntheses often lead to unstable conjugates being unsuitable for use. Particularly relevant is the question of obtaining conjugates of GNPs with antibodies. The high variability of the composition of antibodies impedes the development of a universal technique for obtaining such conjugates. Fairly often, the conjugates are unstable and quickly lose activity during storage $[19,20]$, which is primarily a result of the process of particle aggregation [21].

Aggregation of metal nanoparticles is accompanied by significant changes in their adsorption spectra. This property has been successfully used in various homogeneous biosensors [22-24]. However, for heterogeneous bioanalytical systems, for example, immunochromatographical ones, aggregation of nanoconjugates leads to a lost of their mobility and analytical signals. For this reason, obtaining stable non-aggregating conjugates of metal nanoparticles with antibodies is an important task. To solve this problem, a number of covalent conjugation methods have been developed, for example, using 2-(N-morpholino) ethanesulfonic acid and 3-(N-morpholino)propanesulfonic acid [25]. However, simple physical adsorption is still the most commonly used method for obtaining such conjugates [26]. In this regard, there is a need for studying factors that affect the aggregation of nanoparticles during their conjugation with antibodies.

In this paper we consider an example of obtaining conjugates of a monoclonal antibody preparation with GNPs with non-stable aggregating product. The reasons for reducing their stability are investigated, and a method for solving this problem is proposed.

\section{Materials and Methods}

The following main reagents were used in the work: tween-20, sodium azide, and hydrochloric acid (Chimmed, Moscow, Russia), Tris (Sigma-Aldrich, St. Louis, USA), chloroauric acid (Sigma-Aldrich, USA), bovine serum albumin (BSA) - Boval Biosolutions (Fort Worth, USA), monoclonal antibodies 2H3C6 (Mab 2H3C6) against secretory protein MPT64 of Mycobacterium tuberculosis, and monoclonal antibody 2H2F6 against the structural protein of the sharkey plum virus (Mab2H2F6), which is manufactured by the Central Tuberculosis Research Institute (Moscow, Russia). Protein concentration was determined using the Micro BCA Protein Assay Kit (Thermo Fisher Scientific, Waltham, USA) according to the manufacturer's protocol (https://assets.thermofisher.com/TFS-Assets/LSG/manuals/ MAN0011237_Micro_BCA_Protein_Asy_UG.pdf).

\subsection{Obtaining GNPS}

To obtain GNPs with an average diameter of $25 \mathrm{~nm}$, a variant of the Frens method based on the reduction of $\mathrm{Au}$ (III) by citrate was applied [27]. Chloroauric acid ( $2.95 \mathrm{~mL}$ of $0.34 \%$ water solution) was added to $97.5 \mathrm{~mL}$ of boiling deionized water. The mixture was boiled for 2 min with stirring. Then, $1.44 \mathrm{~mL}$ of a $1 \%$ sodium citrate solution was added, stirred at maximum speed, boiled for $30 \mathrm{~min}$, cooled to room temperature, and stored at $+4{ }^{\circ} \mathrm{C}$.

\subsection{Determination of GNP Sizes by Transmission Electron Microscopy}

GNP preparations were applied to 200 mesh hexagonal copper grids coated with formvar film (SPI Supplies, West Chester, USA). Microscopic analysis was performed on a JEM-100 CX/SEG instrument (Jeol, Akishima, Japan). The obtained microphotographs were scanned to produce 1200 dpi black and white images, and 152 images of particles were processed using the Image Tool program (University of Texas Health Science Center at San Antonio, San Antonio, USA). 


\subsection{Preparation and Purification of Monoclonal Antibodies}

Monoclonal antibodies were obtained by fusion of spleen immune cells of hyperimmune mice with HAT-sensitive myeloma SP2/0. Cell cultures were grown in 96-well plates in $5 \% \mathrm{CO}_{2}$ in a $\mathrm{CO}_{2}$ incubator (Queue, East Lyme, USA) in RPMI1640 culture media with sequential addition of HAT (hypoxanthine-aminopterin-thymidine) and HT (hypoxanthine-thymidine) supplements (Sigma-Aldrich, USA). The growth was controlled basing on changes in the number of cells in the wells; a preliminary comparative assessment of growth in different wells was performed using an inverted microscope (Olympus, Shinjuku, Japan). The medium for in vitro growth of hybridomas contained $10 \%$ fetal serum (from which immunoglobulins were removed by chromatography).

Immunoaffinity chromatography on Sepharose with covalently bound to proteins A and G (HiTrap HP, GE Healthcare) was used for cleaning fetal serum and monoclonal antibodies. Supernatants of hybridomas or fetal serum were passed through columns with the suitable sorbent in FPLC (Pharmacia, Stockholm, Sweden). The columns were washed with PBS. Elution of bound antibodies was initiated by a chaotropic agent- $0.3 \mathrm{M}$ glycine ( $\mathrm{pH}$ 3.0). After the regeneration sorbent by PBS the procedure was repeated. The collected samples were dialyzed against PBS overnight at $4{ }^{\circ} \mathrm{C}$. Concentration of immunoglobulins was carried out on ultrafiltration cells (Amicon, Tampa, USA) onto Biomax 10000NMWL, PBGC 02, 510 filters (Millipore, Burlington, USA).

\subsection{Obtaining of Flocculation Dependence}

To determine the stabilizing concentration of proteins, the flocculation method was used. Protein solutions in concentrations from 0 to $20 \mu \mathrm{g} / \mathrm{mL}$ were added to the GNPs preparation, mixed, and incubated at room temperature. Then $10 \% \mathrm{NaCl}$ was added to each sample, mixed, and, after a 10-min incubation, the optical density of the solution was measured at $580 \mathrm{~nm}$.

\subsection{Immobilization of Antibodies on GNPs for Immunochromatography}

The GNP solution was adjusted with potassium carbonate $(0.2 \mathrm{M})$ to a $\mathrm{pH}$ of 8.5-9.0. Thereafter, IgG was added to the solution to a final concentration of $10 \mu \mathrm{g} / \mathrm{mL}$. The mixture was incubated for $30 \mathrm{~min}$; then, $10 \%$ BSA (1/40 by volume) was added and retained for another $10 \mathrm{~min}$ with vigorous stirring. GNPs were precipitated by centrifugation at $10,000 \times g$ and $4{ }^{\circ} \mathrm{C}$ for $15 \mathrm{~min}$. A precipitate was taken, and $10 \mathrm{mM}$ Tris- $\mathrm{HCl}$ buffer, $\mathrm{pH} 8.5$, with $1 \% \mathrm{BSA}$ and $1 \%$ sucrose, was added.

\subsection{SDS Electrophoresis in Polyacrylamide Gel}

Electrophoretic analysis of the antibody preparation was performed according to the Laemmli method [28]; $12.5 \%$ or $15 \%$ polyacrylamide gels were used. The polymerization was initiated by the addition of ammonium persulfate and tetramethylethylenediamine to a final concentration of $0.1 \%$. Samples for electrophoresis were prepared as follows: concentrated sample buffer $(0.25 \mathrm{M}$ Tris- $\mathrm{HCl}$, $8 \%$ SDS, $40 \%$ glycerol, $0.004 \%$ bromophenol blue, and $5 \%$ mercaptoethanol, $\mathrm{pH} 6.8$ ) was added to the protein solution $(v / v=1: 4)$ and incubated at $100{ }^{\circ} \mathrm{C}$ for $5 \mathrm{~min}$. Electrophoresis was performed on a plate $1 \mathrm{~mm}$ thick and $13 \mathrm{~cm}$ wide at a current strength of $20 \mathrm{~mA}$ until the leading dye entered the separating gel. Then, the current strength was increased to $40 \mathrm{~mA}$. After electrophoresis, the gel was placed in 10\% acetic acid for $30 \mathrm{~min}$ to fix the proteins and remove SDS. Next, the gels were stained with a Coomassie solution (0.2\% Coomassie Blue R-250, 20\% isopropanol, 10\% acetic acid) for $1 \mathrm{~h}$, and excess dye was removed by heating the colored gel in a bath of distilled water.

\subsection{Characterization of the Proteins Solutions by Asymmetrical Flow Field-Flow Fractionation (AF4)}

The fractionations were performed by a Wyatt Eclipse 3+ Separation System (Wyatt Technology, Santa Barbara, CA, USA) with an autosampler and pump (Agilent Technologies, Santa Clara, CA, USA). A 5-kDa MW cutoff regenerated cellulose membrane (Microdyn-Nadir, Wiesbaden, Germany) was used for separation in the $275-\mathrm{mm}$ channel with a $350-\mu \mathrm{m}$ thick spacer. The channel was sequentially 
connected with a UV/VIS detector (Agilent Technologies, USA), Dawn HELEOS II multi-angle light-scattering detector, and Optilab T-Rex refractometer (both from Wyatt Technology, Santa Barbara, USA).

Solutions of BSA and IgG fraction 10-30 kDa (the fraction was additionally concentrated 20 times by centrifugation through $3 \mathrm{kDa}$ filters) in $10 \mathrm{mM} \mathrm{Na}$-carbonate buffer, $\mathrm{pH}=9.0$, were prepared, and $80 \mu \mathrm{L}$ of the solutions were loaded into the AF4 system at a rate of $0.2 \mathrm{~mL} / \mathrm{min}$. The focusing time during the loading was $2 \mathrm{~min}$. The carrier fluids were the same as the buffers for the preparation of BSA and IgG solutions. The main flow rate in the channel was $1 \mathrm{~mL} / \mathrm{min}$, and the focus flow rate was $1 \mathrm{~mL} / \mathrm{min}$. Separation was performed at a linear rate gradient of the cross flow from 5 to $0.1 \mathrm{~mL} / \mathrm{min}$ (10 min). The registered data were analyzed using ChemStation v.B.04.03 (Agilent Technologies, Santa Clara, USA) and Astra v.6.1.1.17 (Wyatt Technology, Santa Barbara, USA) software.

The described above AF4 measurements were conducted using the Shared-Access Equipment Centre "Industrial Biotechnology" of the Federal Research Centre "Fundamentals of Biotechnology" Russian Academy of Sciences (A.N. Bach Institute of Biochemistry RAS), Moscow, Russia.

\subsection{Production of Immunochromatographic Test Systems}

For the formation of the immunochromatographic system, a set of mdi Easypack membranes from Advanced Microdevices (Ambala Cantt, India) was used, including a CNPC-SN12 L2-P25 working membrane (pore size $15 \mu \mathrm{m}$ ), a PT-R5 conjugate membrane, and a GFB-R4 membrane for applying a sample adsorbing membrane AP 045. The PT-R5 membrane was also used for BSA deposition.

The recombinant antigen of M. tuberculosis, MTB64, was used to form the analytical zone, and $2 \mu \mathrm{L}$ of a solution of protein in $50 \mathrm{~mm}$ phosphate buffer was applied on $1 \mathrm{~cm}$ of the strip. The GNP conjugate with antibodies was applied in a dilution corresponding to optical density at $520 \mathrm{~nm}=2$, in a volume of $10 \mu \mathrm{L}$ per $1 \mathrm{~cm}$ of the band. For the application of reagents, an IsoFlow dispenser from Imagene Technology (Hanover, USA) was used. After applying the reagents, the membranes were dried for at least $24 \mathrm{~h}$ in a room with controlled temperature and humidity. Membrane sheets coated with immunoreagents were cut into individual test strips $3.5 \mathrm{~mm}$ wide.

\section{Results and Discussion}

\section{Transmission electron microscopy of GNPs}

Dimensional characteristics of GNPs were evaluated by transmission electron microscopy. According to the data obtained, the synthesized preparation had an average diameter of nanoparticles about $24.9 \mathrm{~nm}$, the average deviation was $5.3 \mathrm{~nm}$ in a sample of 152 particles. The corresponding distribution is shown in Figure 1.

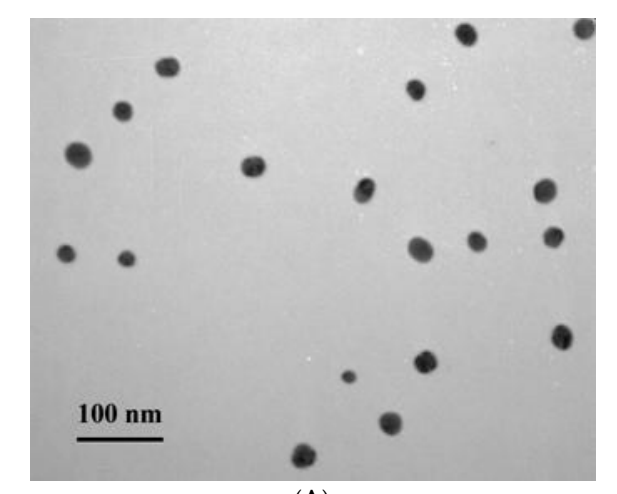

(A)

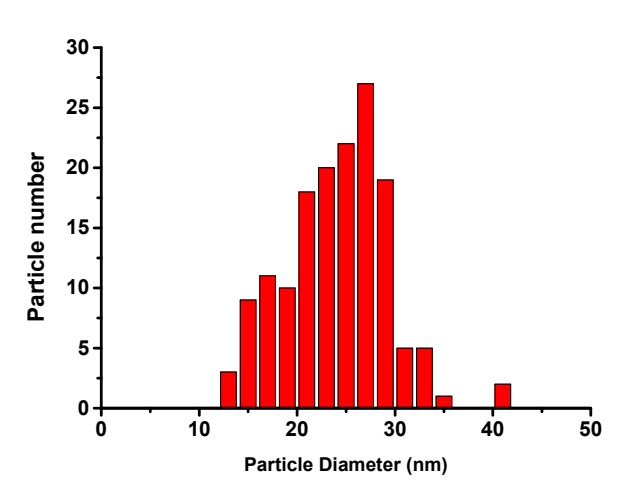

(B)

Figure 1. (A) TEM image of gold nanoparticles. (B) A histogram of the gold nanoparticles (GNPs) distribution by diameter (basing on TEM data). $n=152$. 


\subsection{Flocculation Dependence}

The protein adsorption on GNPs is often controlled by the optical density of the colloidal solution at $580 \mathrm{~nm}$ after the addition of $10 \% \mathrm{NaCl}$ [29]. Typically, optical density increases with increasing protein concentration, reaches a maximum, and begins to decline, reaching a plateau. It is believed that reaching a plateau of flocculation dependence corresponds to the composition of conjugates with maximum binding ability that are necessary for highly sensitive immunoassays in noncompetitive formats. We obtained this form of the flocculation curve upon conjugation of Mab 2H2F6 antibodies with GNPs. The preparation of antibodies Mab 2H2F6 did not cause aggregation of nanoparticles (and changes in the optical density of the colloidal solution) by itself. When $10 \% \mathrm{NCl}$ was added, changes in optical density were observed depending on the concentration of antibodies (see Figure 2A).

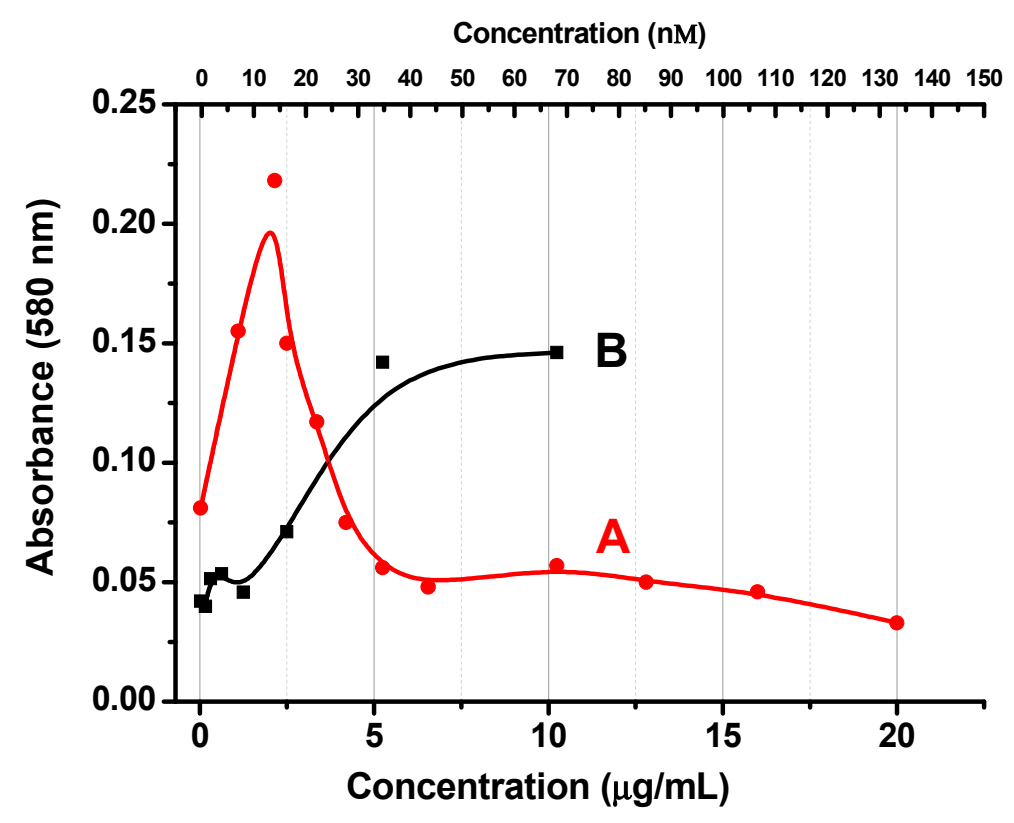

Figure 2. Flocculation curves of GNP conjugates with antibodies. (A; red curve), after adding Mab 2H2F6 and 10\% NaCl. (B; black curve), after adding Mab2H3C6.

When antibodies Mab 2H3C6 were added to the colloidal solution of the GNPs, a fundamentally different dependence was observed: Nanoparticles were aggregated immediately after mixing with antibodies (Figure 2B). This flocculation did not require the addition of $10 \% \mathrm{NaCl}$ and reflected the unsuitability of the conjugates for further analytical use due to their instability. Monoclonal antibodies do not always behave this way. As a rule, conjugation of monoclonal antibodies with GNPs produces stable nonaggregating conjugates (as was the case with Mab2H2F6). However, it is known that the aggregation stability of GNPs with monoclonal antibodies is significantly different for different antibody preparations [30]. We thus studied the cause of the aggregation of nanoconjugates with the used Mab 2H3C6 preparation.

\subsection{Centrifugation and Optical Spectroscopy}

To determine the cause of the destabilization of the colloid by monoclonal antibodies, Mab2H3C6 was first filtered through Amicon Ultra centrifugal filters with different transmittance. In each centrifugation, the antibodies were concentrated four times and then diluted with $10 \mathrm{~mm}$ Tris- $\mathrm{HCl}$ buffer, $\mathrm{pH} 8.5$ to the original volume.

It was found that filtering Mab2H3C 6 through filters that pass molecules of less than $30 \mathrm{kDa}$ reduces the aggregation ability of the preparation (Figure 3). For samples 1 and 2 (first and second centrifugation cycles) the aggregates having spectral peak at $580 \mathrm{~nm}$, as it follows from [31], were formed and the colloidal solution became unstable and turbid. Sample 3 (third cycle) had an additional adsorption at 
$580 \mathrm{~nm}$ and the main peak at $525 \mathrm{~nm}$. Spectra for samples 4 and 5 (fourth and fifth cycles) approaching a native colloidal solution of naked GNPs, which indicates a non-aggregated state.

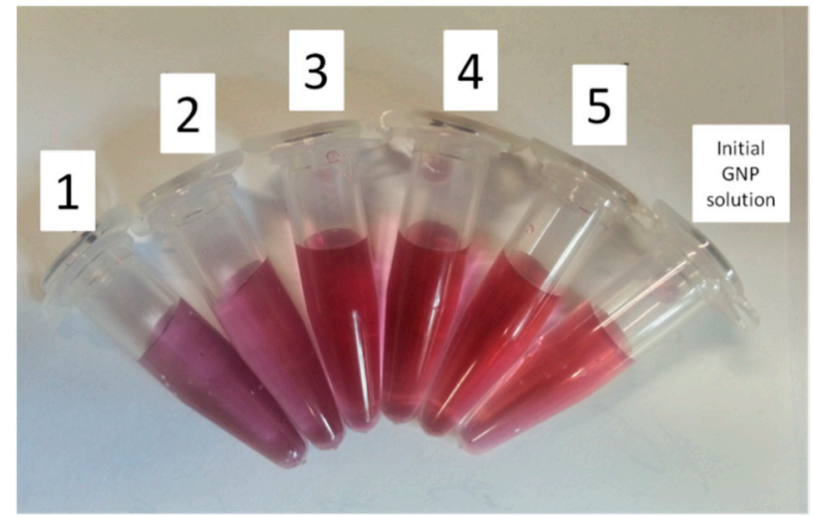

(A)

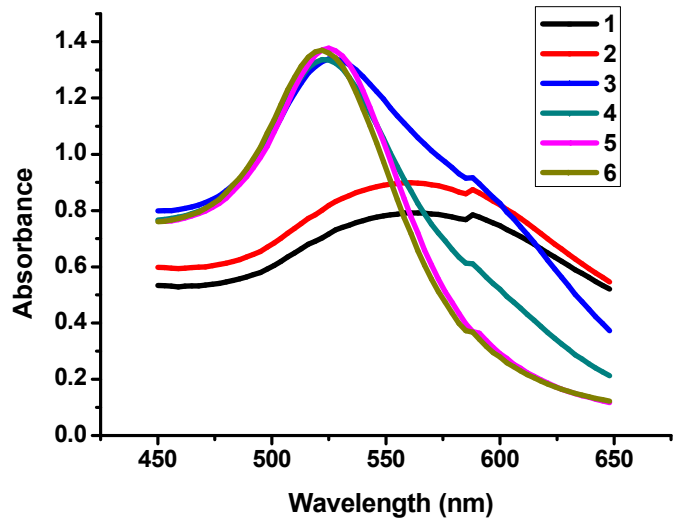

(B)

Figure 3. Dependence of the degree of aggregation of GNP conjugates with Mab 2H3C6 on the number of centrifugation cycles through Amicon Ultra $30 \mathrm{kDa}$ filters. 1-5: centrifugation cycles, 6: initial solution of GNPs. (A) The appearance of colloidal solutions after adding $10 \mu \mathrm{g} / \mathrm{mL} \mathrm{Mab} \mathrm{2H3C6.} \mathrm{(B)} \mathrm{The}$ absorbance spectra of $1-6$ solutions.

In the case of filters with a cutoff threshold of up to $10 \mathrm{kDa}$, the aggregating ability of the preparation was preserved even after six centrifugation cycles (Figure 4). In addition, the fraction of the solution that passed through the $30 \mathrm{kDa}$ filters, when mixed with GNPs, caused their immediate aggregation (Figure 4, curve 3). From these data it follows that the reason for the aggregation was high molecular weight impurities with a mass of not less than $10 \mathrm{kDa}$ and not more than $30 \mathrm{kDa}$. Note that the monoclonal antibody preparations were purified by affinity chromatography on a column of streptococcal protein $\mathrm{G}$ and should not have contained foreign macromolecular impurities.

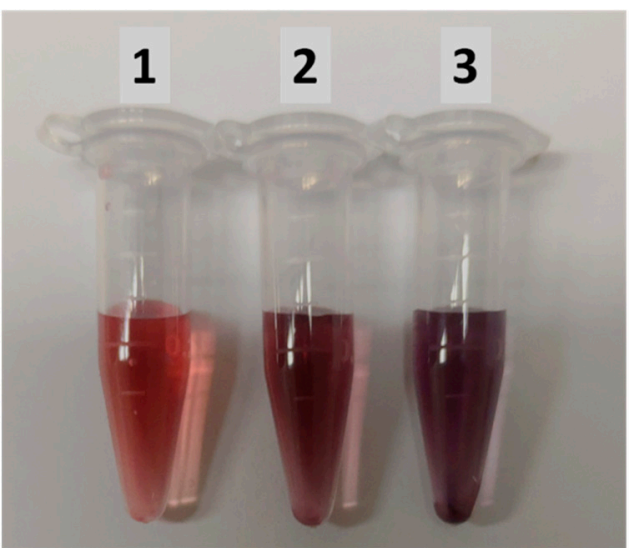

(A)

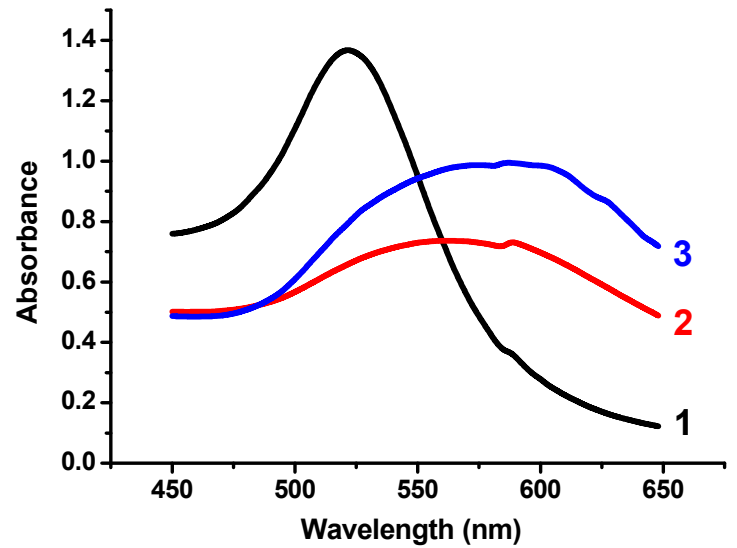

(B)

Figure 4. Aggregation of the GNPs conjugates. (A) The appearance of colloidal solutions, 1 is the initial solution of the nanoparticles, 2 is the colloidal solution after adding $10 \mu \mathrm{g} / \mathrm{mL}$ of Mab2H3C6 centrifuged six times through the $10 \mathrm{kDa}$ Amicon Ultra filters, 3 is the colloidal solution after adding fraction of 10-30 kDa. (B) The absorbance spectra of 1-3 solutions.

\subsection{SDS Electrophoresis in Polyacrylamide Gel}

To establish the high molecular weight composition of the Mab 2H3C6 solution, denaturing polyacrylamide gel electrophoresis was performed. The results presented in Figure 5 show two major bands corresponding to light chains $(25 \mathrm{kDa})$ and heavy chains $(50 \mathrm{kDa})$ of 
IgG. Extraneous impurities in the range of molecular masses of 10-30 kDa were not observed. Therefore, we hypothesized that compounds aggregating NPPs were fragments of decayed antibodies, namely their light chains.

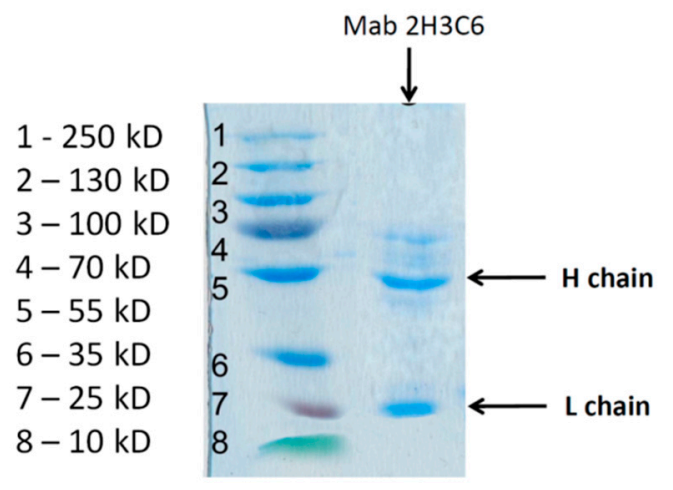

Figure 5. Results of SDS-electrophoresis of Mab 2H3C6 in a polyacrylamide gel.

\subsection{Asymmetrical Flow Field-Flow Fractionation}

It is well known that immunoglobulins are susceptible to spontaneous decomposition during storage [32]. However, the rate of this process depends on many factors [33-36]. It was necessary to confirm the presence of fragments of the antibodies in the initial solution because these fragments could be formed only during electrophoresis. Therefore, we additionally investigated the fraction 10-30 kDa obtained after centrifugation of a monoclonal antibody preparation (clone 2H3C6) by a nondestructive method-asymmetrical flow field-flow fractionation (AF4). Using the Micro BCA Protein Assay Kit, we have shown that the content of IgG fragments in the obtained fraction 10-30 $\mathrm{kDa}$ was $1.7 \%$ (by weight) from the initial IgG content. The fraction was additionally concentrated 20 times by centrifugation through $3 \mathrm{kDa}$ filters. The obtained sensograms (Figure 6) confirmed the presence of a fraction of protein molecules with a molecular weight lower than that of BSA $(66 \mathrm{kDa})$. The main peak of the AF4 sensogram for the studied preparation accords to IgG fragments with a molecular weight about $25 \mathrm{kDa}$, which we associated with IgG light chains (L). A minor peak in the 50 $\mathrm{kDa}$ region was also detected, which may be associated with partial transmission of IgG heavy chains by Amicon Ultra $30 \mathrm{kDa}$ filters or by aggregation of IgG light chains.

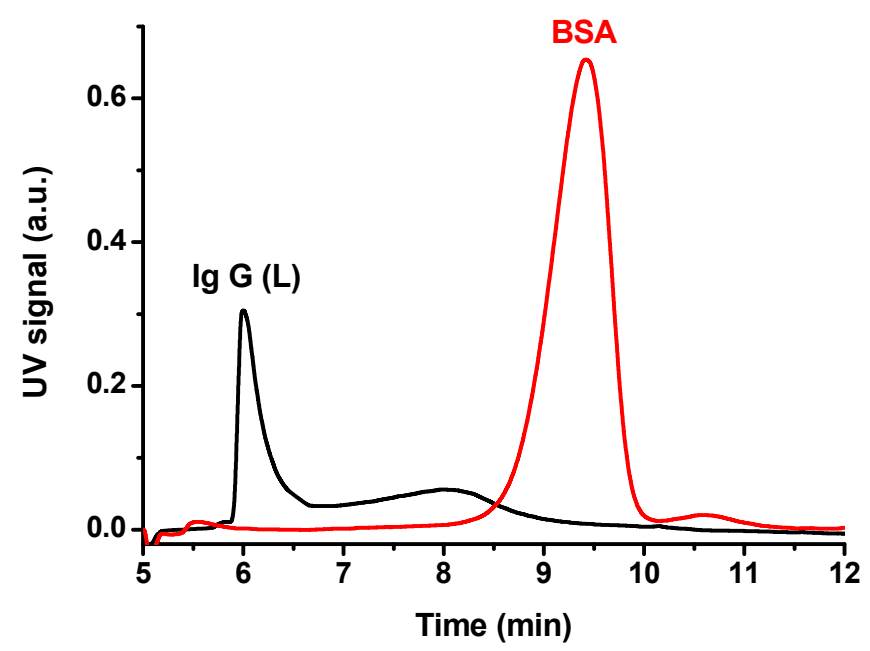

Figure 6. Asymmetrical flow field-flow fractionation of the fraction 10-30 kDa obtained after centrifugation of a monoclonal antibody preparation (clone $2 \mathrm{H} 3 \mathrm{C} 6$; black curve), and BSA as a reference protein (red curve). The fraction was additionally concentrated 20 times by centrifugation through $3 \mathrm{kDa}$ filters. 


\subsection{Aggregation Stability of GNPs with Various Fractions of the 2H3C6 Preparation}

We associated the aggregation of GNPs precisely with the presence of $\operatorname{IgG}(\mathrm{L})$, since the fraction of the $2 \mathrm{H} 3 \mathrm{C} 6$ preparation that did not pass through Amicon Ultra $30 \mathrm{kDa}$ filters and thus contained heavy chains and full-sized IgG, did not cause aggregation of GNPs.

Thus, to obtain nonaggregating conjugates of GNPs with Mab2H3C6, it is necessary to separate the fraction with a molecular weight of less than $30 \mathrm{kDa}$ from the antibody preparation. For example, after 6-fold centrifugation through Amicon Ultra $30 \mathrm{kDa}$, Mab 2H3C6 preparations did not aggregate GNPs, and stable conjugates were obtained.

Heavy chains did not cause aggregation of nanoparticles. It follows from the result of the experiment with the separated fraction of compounds with molecular weight $>30 \mathrm{kDa}$. This fraction containing heavy chains did not aggregate GNPs. The obtained fraction was additionally centrifuged through filters with cut-off $100 \mathrm{kDa}$ to separate heavy chains (50-55 kDa) and full-sized IgG (150-160 kDa). None of these two fractions aggregated GNPs.

\subsection{Immunochromatography}

The binding of antibodies to particles and the preservation of their functional activity were confirmed by immunochromatography. For this, the obtained conjugates were passed through nitrocellulose membranes with an immobilized antigen: recombinant protein MPT64 of M. tuberculosis. The results shown in Figure 7 confirm the high binding ability of the obtained GNP conjugates with Mab 2H3C6 (binding was recorded at antigen concentrations up to $10 \mathrm{pg} / \mathrm{mL}$ ). At the same time, conjugates obtained by the method without the centrifugation of Mab2H3C6 through Amicon Ultra $30 \mathrm{kDa}$ were not suitable for immunochromatography due to the sticking of aggregated particles in the pores of the nitrocellulose membrane.

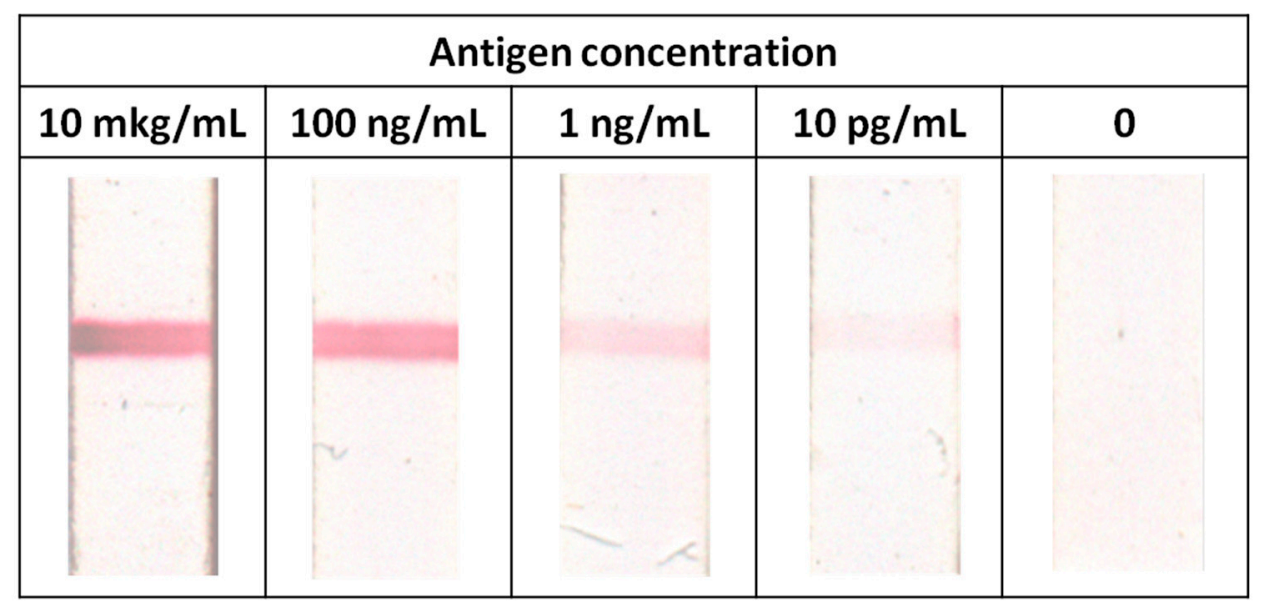

Figure 7. Immunochromatographic testing of the binding of GNP conjugates to Mab and M. tuberculosis antigen MPT64.

Thus, the addition of a stage of antibody purification from the fraction $<30 \mathrm{kDa}$ to the method for producing conjugates led to solving the problem of GNPs and obtaining stable conjugates with high binding ability.

\section{Conclusions and Outlook}

Clarification of the general regulations of GNPs aggregation by antibodies requires additional studies, including the characterization of various aggregating monoclonal preparations. Differences between aggregating and non-aggregating preparations could be directly related to the amino acid composition and its influence on the structure of proteins, as well as to the peculiarities of 
synthesis and transformation of immunoglobulins, leading to the presence of fragments of antibodies in the preparations.

Thus, high affinity of sulfur-containing chemical groups to gold surfaces [37,38], structural changes of antibodies in the course of their immobilization on gold surfaces and GNPs [39], the effect of immobilized proteins on the electrical properties of metal surfaces, potentially manifesting itself in decreased stability of colloidal solutions $[40,41]$ were described.

J. Goossens et al. [42], studying the aggregation of GNPs by nanobodies (molecules with an incomplete structure of immunoglobulins), suggest two possible mechanisms for the aggregation phenomenon: (1) sorption of the protein on GNP leads to its denaturation, the appearance of hydrophobic groups on the surface and the aggregation provoked by these groups, and (2) cross-linking of GNPs by positively charged antibody fragments. Different isoelectric points of whole antibodies and their fragments can affect the variability of the aggregation stability.

The presence of free light chains immunoglobulins in the preparation can be caused by either violations of the ratio of heavy and light chain synthesis in antibody-producing cells, or fragmentation of native molecules in contaminated preparations. The variation in synthesis of heavy and light chains for a significant part of monoclones was noted in $[43,44]$. Control of the absence of antibodies destruction during their storage should be considered as an important element in assessing the reactants quality in the manufacture of immunochromatographic test systems. Such techniques as asymmetrical flow field-flow fractionation, size-exclusion chromatography, AgNPs-based array [24], etc. could be used for this purpose.

Aggregation instability of conjugates of GNPs and antibodies is a frequent problem when developing analytical systems based thereon. Often, the problem is solved by screening various antibody clones to find the most stable conjugates. Our work demonstrated that a partial destruction of antibodies might be the reason for the decrease in the stability of conjugates. Therefore, in the case of a problem of conjugate aggregation, antibody preparations should be purified from fragments of their decay. This proposal can help developers build nanoconjugate-based systems with enhanced functionality.

Author Contributions: Conceptualization, D.V.S., A.V.Z. and B.B.D.; investigation, D.V.S., I.V.S., V.G.A., I.V.K., S.S.B., V.Y.G.; methodology, D.V.S., A.V.Z., I.V.S., V.G.A., I.V.K., S.S.B., V.Y.G. and B.B.D.; resources, D.V.S., I.V.S., V.G.A., I.V.K., S.S.B. and V.Y.G.; validation, D.V.S., I.V.S., V.G.A.; visualization, D.V.S. and A.V.Z.; writing (original draft), D.V.S., I.V.S., V.G.A., A.V.Z. and B.B.D.; Writing (review and editing), D.V.S., A.V.Z. and B.B.D. All authors have read and agreed to the published version of the manuscript.

Funding: This study was financially supported by the Ministry of Science and Higher Education of the Russian Federation (grant agreement No. 14.613.21.0080 on 22.11.2017, unique identifier RFMEFI613170080).

Conflicts of Interest: The authors declare that they have no known competition for financial interests or personal relationships that could have appeared to influence the work reported in this paper.

\section{References}

1. Aldewachi, H.; Chalati, T.; Woodroofe, M.N.; Bricklebank, N.; Sharrack, B.; Gardiner, P. Gold nanoparticle-based colorimetric biosensors. Nanoscale 2018, 10, 18-33. [CrossRef]

2. Golchin, K.; Golchin, J.; Ghaderi, S.; Alidadiani, N.; Eslamkhah, S.; Eslamkhah, M.; Davaran, S.; Akbarzadeh, A. Gold nanoparticles applications: From artificial enzyme till drug delivery. Artif. Cells Nanomed. Biotechnol. 2018, 46, 250-254. [CrossRef]

3. Verma, M.S.; Rogowski, J.L.; Jones, L.; Gu, F.X. Colorimetric biosensing of pathogens using gold nanoparticles. Biotechnol. Adv. 2015, 33, 666-680. [CrossRef] [PubMed]

4. Saha, K.; Agasti, S.S.; Kim, C.; Li, X.; Rotello, V.M. Gold nanoparticles in chemical and biological sensing. Chem. Rev. 2012, 112, 2739-2779. [CrossRef] [PubMed]

5. Dreaden, E.C.; Alkilany, A.M.; Huang, X.; Murphy, C.J.; El-Sayed, M.A. The golden age: Gold nanoparticles for biomedicine. Chem. Soc. Rev. 2012, 41, 2740-2779. [CrossRef] [PubMed]

6. Dykman, L.; Khlebtsov, N. Gold nanoparticles in biomedical applications: Recent advances and perspectives. Chem. Soc. Rev. 2012, 41, 2256-2282. [CrossRef] [PubMed] 
7. Daniel, M.-C.; Astruc, D. Gold nanoparticles: Assembly, supramolecular chemistry, quantum-size-related properties, and applications toward biology, catalysis, and nanotechnology. Chem. Rev. 2004, 104, 293-346. [CrossRef] [PubMed]

8. Lee, J.H.; Cho, H.Y.; Choi, H.K.; Lee, J.Y.; Choi, J.W. Application of gold nanoparticle to plasmonic biosensors. Int. J. Mol. Sci. 2018, 19, 2021. [CrossRef]

9. Sapsford, K.E.; Algar, W.R.; Berti, L.; Gemmill, K.B.; Casey, B.J.; Oh, E.; Stewart, M.H.; Medintz, I.L. Functionalizing nanoparticles with biological molecules: Developing chemistries that facilitate nanotechnology. Chem. Rev. 2013, 113, 1904-2074. [CrossRef]

10. Anniebell, S.; Gopinath, S.C. Polymer conjugated gold nanoparticles in biomedical applications. Curr. Medic. Chem. 2018, 25, 1433-1445. [CrossRef]

11. Zeng, S.W.; Yong, K.T.; Roy, I.; Dinh, X.P.; Yu, X.; Luan, F. A review on functionalized gold nanoparticles for biosensing applications. Plasmonics 2011, 6, 491-506. [CrossRef]

12. Jeong, H.H.; Choi, E.; Ellis, E.; Lee, T.C. Recent advances in gold nanoparticles for biomedical applications: From hybrid structures to multi-functionality. J. Mater. Chem. B 2019, 7, 3480-3496. [CrossRef]

13. Arruebo, M.; Valladares, M.; González-Fernández, Á. Antibody-conjugated nanoparticles for biomedical applications. J. Nanomater. 2009, 2009, 37. [CrossRef]

14. Nobs, L.; Buchegger, F.; Gurny, R.; Allémann, E. Current methods for attaching targeting ligands to liposomes and nanoparticles. J. Pharm. Sci. 2004, 93, 1980-1992. [CrossRef] [PubMed]

15. Jazayeri, M.H.; Amani, H.; Pourfatollah, A.A.; Pazoki-Toroudi, H.; Sedighimoghaddam, B. Various methods of gold nanoparticles (GNPs) conjugation to antibodies. Sens. Bio-Sens. Res. 2016, 9, 17-22. [CrossRef]

16. Sellers, H.; Ulman, A.; Shnidman, Y.; Eilers, J.E. Structure and binding of alkanethiolates on gold and silver surfaces: Implications for self-assembled monolayers. J. Am. Chem. Soc. 1993, 115, 9389-9401. [CrossRef]

17. Lacerda, S.H.D.P.; Park, J.J.; Meuse, C.; Pristinski, D.; Becker, M.L.; Karim, A.; Douglas, J.F. Interaction of gold nanoparticles with common human blood proteins. ACS Nano 2009, 4, 365-379. [CrossRef]

18. Sen, T.; Haldar, K.K.; Patra, A. Au nanoparticle-based surface energy transfer probe for conformational changes of BSA protein. J. Phys. Chem. C 2008, 112, 17945-17951. [CrossRef]

19. Xiulan, S.; Xiaolian, Z.; Jian, T.; Zhou, J.; Chu, F.S. Preparation of gold-labeled antibody probe and its use in immunochromatography assay for detection of aflatoxin B1. Int. J. Food Microbiol. 2005, 99, 185-194. [CrossRef]

20. Gupta, A.; Moyano, D.F.; Parnsubsakul, A.; Papadopoulos, A.; Wang, L.S.; Landis, R.F.; Das, R.; Rotello, V.M. Ultrastable and biofunctionalizable gold nanoparticles. ACS Appl. Mater. Interfaces 2016, 8, 14096-14101. [CrossRef]

21. Filbrun, S.L.; Filbrun, A.B.; Lovato, F.L.; Oh, S.H.; Driskell, E.A.; Driskell, J.D. Chemical modification of antibodies enables the formation of stable antibody-gold nanoparticle conjugates for biosensing. Analyst 2017, 142, 4456-4467. [CrossRef] [PubMed]

22. Berlina, A.N.; Zherdev, A.V.; Dzantiev, B.B. Progress in rapid optical assays for heavy metal ions based on the use of nanoparticles and receptor molecules. Microchim. Acta 2019, 186, 172. [CrossRef] [PubMed]

23. Iarossi, M.; Schiattarella, C.; Rea, I.; De Stefano, L.; Fittipaldi, R.; Vecchione, A.; Ventura, B.D. Colorimetric immunosensor by aggregation of photochemically functionalized gold nanoparticles. ACS Omega 2018, 3, 3805-3812. [CrossRef] [PubMed]

24. Lizoń, A.; Wytrwal-Sarna, M.; Gajewska, M.; Drożdż, R. Silver nanoparticle-based assay for the detection of immunoglobulin free light chains. Materials 2019, 12, 2981. [CrossRef]

25. Busch, R.T.; Karim, F.; Weis, J.; Sun, Y.; Zhao, C.; Vasquez, E.S. Optimization and structural stability of gold nanoparticle-antibody bioconjugates. ACS Omega 2019, 4, 15269-15279. [CrossRef]

26. Wang, Z.; Ma, L. Gold nanoparticle probes. Coord. Chem. Rev. 2009, 253, 1607-1618. [CrossRef]

27. Frens, G. Controlled nucleation for the regulation of the particle size in monodisperse gold suspensions. Nat. Phys. Sci. 1973, 241, 20-22. [CrossRef]

28. Laemmli, U.K. Cleavage of structural proteins during the assembly of the head of bacteriophage T4. Nature 1970, 227, 680-685. [CrossRef]

29. Hermanson, G.T. Bioconjugate Techniques, 3rd ed.; Academic Press: New York, NY, USA, 2013; p. 1200. ISBN 9780123822390.

30. Lai, Y.H.; Koo, S.; Oh, S.H.; Driskell, E.A.; Driskell, J.D. Rapid screening of antibody-antigen binding using dynamic light scattering (DLS) and gold nanoparticles. Anal. Methods 2015, 7, 7249-7255. [CrossRef] 
31. Safenkova, I.V.; Zherdev, A.V.; Dzantiev, B.B. Factors influencing the detection limit of the lateral-flow sandwich immunoassay: A case study with potato virus X. Anal. Bioanal. Chem. 2012, 403, 1595-1605. [CrossRef]

32. Gaza-Bulseco, G.; Liu, H. Fragmentation of a recombinant monoclonal antibody at various pH. Pharm. Res. 2008, 25, 1881-1890. [CrossRef] [PubMed]

33. Ouellette, D.; Alessandri, L.; Piparia, R.; Aikhoje, A.; Chin, A.; Radziejewski, C.; Correia, I. Elevated cleavage of human immunoglobulin gamma molecules containing a lambda light chain mediated by iron and histidine. Anal. Biochem. 2009, 389, 107-117. [CrossRef] [PubMed]

34. Diemel, R.V.; Ter Hart, H.G.; Derksen, G.J.; Koenderman, A.H.; Aalberse, R.C. Characterization of immunoglobulin $\mathrm{G}$ fragments in liquid intravenous immunoglobulin products. Transfusion 2005, 45, 1601-1609. [CrossRef] [PubMed]

35. Vlasak, J.; Ionescu, R. Fragmentation of monoclonal antibodies. MAbs 2011, 3, 253-263. [CrossRef] [PubMed]

36. Liu, H.; May, K. Disulfide bond structures of IgG molecules: Structural variations, chemical modifications and possible impacts to stability and biological function. MAbs 2012, 4, 17-23. [CrossRef]

37. Acres, R.G.; Feyer, V.; Tsud, N.; Cadino, E.; Prince, K.C. Mechanisms of aggregation of cysteine functionalized gold nanoparticles. J. Phys. Chem. C 2014, 118, 10481-10487. [CrossRef]

38. Doyen, M.; Goole, J.; Bartik, K.; Bruylants, G. Amino acid induced fractal aggregation of gold nanoparticles: Why and how. J. Colloid Interface Sci. 2016, 464, 160-166. [CrossRef]

39. Makaraviciute, A.; Ruzgas, T.; Ramanavicius, A.; Ramanaviciene, A. Antibody fragment immobilization on planar gold and gold nanoparticle modified quartz crystal microbalance with dissipation sensor surfaces for immunosensor applications. Anal. Methods 2014, 6, 2134-2140. [CrossRef]

40. Stobiecka, M.; Hepel, M. Effect of buried potential barrier in label-less electrochemical immunodetection of glutathione and glutathione-capped gold nanoparticles. Biosens. Bioelectron. 2011, 26, 3524-3530. [CrossRef]

41. Stobiecka, M.; Chalupa, A.; Dworakowska, B. Piezometric biosensors for anti-apoptotic protein survivin based on buried positive-potential barrier and immobilized monoclonal antibodies. Biosens. Bioelectron. 2016, 84, 37-43. [CrossRef]

42. Goossens, J.; Sein, H.; Lu, S.; Radwanska, M.; Muyldermans, S.; Sterckx, Y.G.J.; Magez, S. Functionalization of gold nanoparticles with nanobodies through physical adsorption. Anal. Methods 2017, 9, 3430-3440. [CrossRef]

43. Bradbury, A.; Plückthun, A. Reproducibility: Standardize antibodies used in research. Nature 2015, 518, 27-29. [CrossRef] [PubMed]

44. Tu, B.; Tieman, B.; Moore, J.; Pan, Y.; Muerhoff, A.S. Myeloma-derived light chain paired with a diagnostic monoclonal antibody hinders immunoassay performance. Monoclon. Antib. Immunodiagn. Immunother. 2017, 36, 113-118. [CrossRef] [PubMed]

(C) 2020 by the authors. Licensee MDPI, Basel, Switzerland. This article is an open access article distributed under the terms and conditions of the Creative Commons Attribution (CC BY) license (http://creativecommons.org/licenses/by/4.0/). 